\title{
Remote Laboratory in Photovoltaics
}

\author{
doi:10.3991/ijoe.v5i3.886
}

\author{
P.A. Cotfas, D.T. Cotfas, D. Ursutiu and C. Samoila \\ Transylvania University of Brasov, Brasov, Romania
}

\begin{abstract}
This paper presents a new concept of studying, understanding and teaching the performance of solar cells. Using NI ELVIS allows the realization of eight laboratory experiments which study all the important parameters of the solar cells. The model used for the equivalent circuit of the solar cell was the "one diode" model. For the realization of control, data acquisition and processing, a complex program was created, with a friendly interface, using the graphical programming language LabVIEW.
\end{abstract}

Index Terms-LabVIEW, NI ELVIS, Photovoltaic, Remote Laboratory, Solar cells, Parameters.

\section{INTRODUCTION}

Renewable energies have become, more than ever, a priority for the European Union. The oil crisis from July 2008 when the price went up to a historical maximum of 147 dollars a barrel, led to a maximum involvement of all resources- political, economical and scientific- in developing the renewable energy available, but also in finding new solutions. Another important factor leading humanity towards the use of renewable energy is the global warming and the effects coming from it.

The efforts of research are thus oriented towards finding new energy sources and raising the efficiency of the already existent ones. The photovoltaic energy is included in this context, the key element for producing the photovoltaic energy being the solar cell. This is a good reason to create a remote laboratory in which the students would be able to understand, learn and consolidate their knowledge of solar cells' functioning by determining and interpreting their major parameters.

How can the functioning of a solar cell be understood? And also the phenomena taking place inside of it? The answer is easy- by making experiments to determine the important parameters of the cell. The interest parameters determined using the $\mathrm{I}-\mathrm{V}$ characteristic are: $\mathrm{I}_{\mathrm{sc}}-$ the short circuit current, $\mathrm{V}_{\mathrm{oc}}$ - the open circuit voltage, $\mathrm{n}$ - the ideality factor of diode, $R_{s}$ - the series resistance, $R_{s h}-$ the shunt resistance, $I_{0}$ - the reverse saturation current, FF the fill factor, $\mathrm{P}_{\max }-$ the maximum power, $\mathrm{V}_{\max }-$ the maximum voltage, $I_{\max }$ the maximum current. The determination of the solar cell parameters is important for two major reasons: for checking the proper functioning of the cells in order to build PV (photovoltaic) systems and for finding the improvement possibilities of the solar cell parameters in the technological process of fabrication.

In order to determine the parameters of the solar cells the I-V (current - voltage) characteristic method is used, implying its raise and interpretation as seen in Fig. 1.

The equation used for the theoretical description and fitting of the characteristic is dependant on the equivalent circuit of the solar cell, see "Fig. 2".

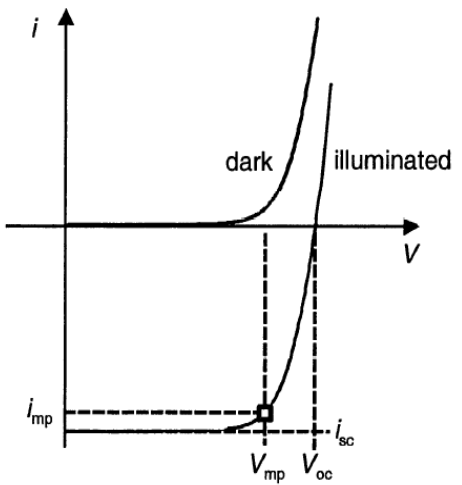

Figure 1. The I-V characteristic for solar cells

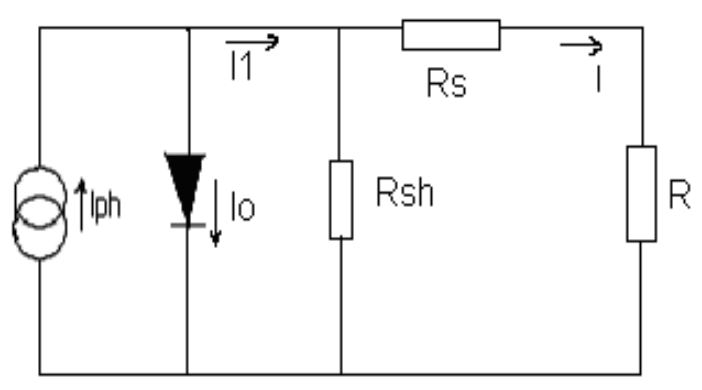

Figure 2. The equivalent circuit of solar cells

To describe the mechanisms taking place inside of a solar cell several models are used. In the realization of experiments and for the data processing within our lab the one diode model was used for the equivalent circuit of the solar cell. The equation (1) mathematically describes the equivalent circuit with one diode and parasite resistances:

$$
I=I_{s c}-I_{o}\left(e^{\frac{q\left(V+I R_{s}\right)}{k T}}-1\right)-\frac{V+I R_{s}}{R_{s h}} .
$$

where: $\mathrm{k}$ is the Boltzmann constant and $\mathrm{T}$ is the temperature in $\mathrm{K}$.

\section{THE LABORATORY}

\section{A. Development}

The development of a remote laboratory leads to costs and space reduction for the lab experiments. The starting point in creating a remote lab was to offer the students the possibility to perform their lab assignments outside the limited classes time period. As the costs need to be low a complex system was chosen as it can be used for several experiments. Thus we chose as a solution the realization 
of the lab using a NI ELVIS protyping platform. The concept realized made possible the development of not less than eight laboratory experiments, all on the same device. The experiments performance by students offers them a lot of information and expertise in the domain of solar cells. The students will be able to understand the importance of the parameters listed above in the study, fabrication and improvement of the solar cells' performance.

Some of the experiments that can be done using the application that was developed are:

- Determination of solar cells parameters using the I-V characteristic, using the Levenberg Marquardt nonlinear fitting procedure, as in [1] and the five parameters method;

- Determination of the series resistance of the photovoltaic cells using the two characteristics method, the area and generalized area methods, the original method developed by our team, "Fig. 3", as in [2],[3],[4];

- Determination of the shunt resistance of the photovoltaic cell, as in [5];

- Study of the solar cell's parameters dependence upon the illumination level;

- Study of the solar cell's parameters dependence upon the temperature;

- Study of the solar cell's parameters dependence upon the incidence angle of the light radiation.

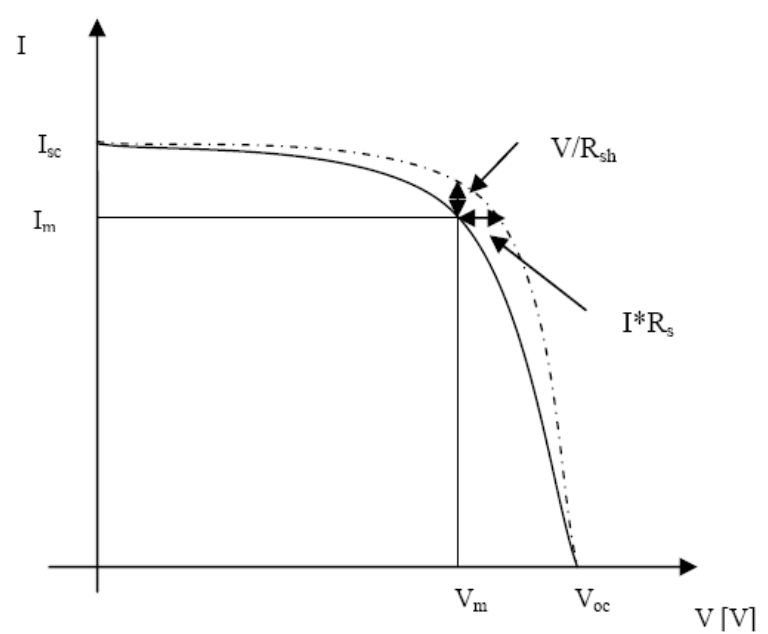

Figure 3. The I-V characteristics for solar cell (full line - real, interrupted line - ideal)

The system for the raising of the I-V characteristics of the solar cells is based on a circuit developed in the Ph.D. thesis of Lecturer D.T. COTFAS, as in [6].

The lab components are:

- The NI-ELVIS with a NI PCI-MIO-16E-1 DAQ board;

- The solar cell with the displacement system;

- The system for rotating the cell at different angles and automatic change of the cells;

- A thermostat to keep the temperature constant during the measurements, as the open circuit voltage decreases with the increase of temperature;

- The automatic system for raising the I-V characteristic of the solar cell;
- The power supply for the light source;

- The PC with the graphical programming language LabVIEW, see "Fig. 4".

The solar cell displacement system is based on a XY recorder. This system is used for the variation of the cell illumination by varying the distance between the cell and a source of light. The light source offers an illumination between $100 \mathrm{~W} / \mathrm{m}^{2}$ and $1000 \mathrm{~W} / \mathrm{m}^{2}$ necessary for the simulation of sunlight.

The rotating system of the cell is based on a step by step motor of $1.8^{0} / \mathrm{step}$, commanded by the DIO ports and the NI board.

The applications for the measurement and control of the system are realized in the graphical programming language LabVIEW. This allows a quick and easy implementation of the measurement and data processing methods necessary for this type of laboratory procedures. In addition to this it makes possible a quick and easy publication of the interfaces on the web and their remote control.

The development of the laboratory was done in two phases: a local phase oriented towards implementing the methods for measurement and parameters of interest calculation for solar cells and a second phase dedicated to the creation of remote control interfaces for studying solar cells (the adaptation of the applications from the first phase to the necessities and conditions of the remote laboratories).

\section{B. The Softwares developed for solar cells characterization}

Complex soft was created using the graphical programming language LabVIEW so that the system becomes fully functional. The soft created to determine the important parameters of the solar cell is a modular one. This allows the development of new applications by simply integrating the new module in the base soft.

In 'Fig. 5" a general application is presented allowing the raising of the I-V characteristics, the calculation of the power $(\mathrm{P}-\mathrm{V})$ characteristic, the determination of the short circuit current, the ideality factor, the open circuit voltage, as well as the calculation of the series and shunt resistances by various methods, as in [7].

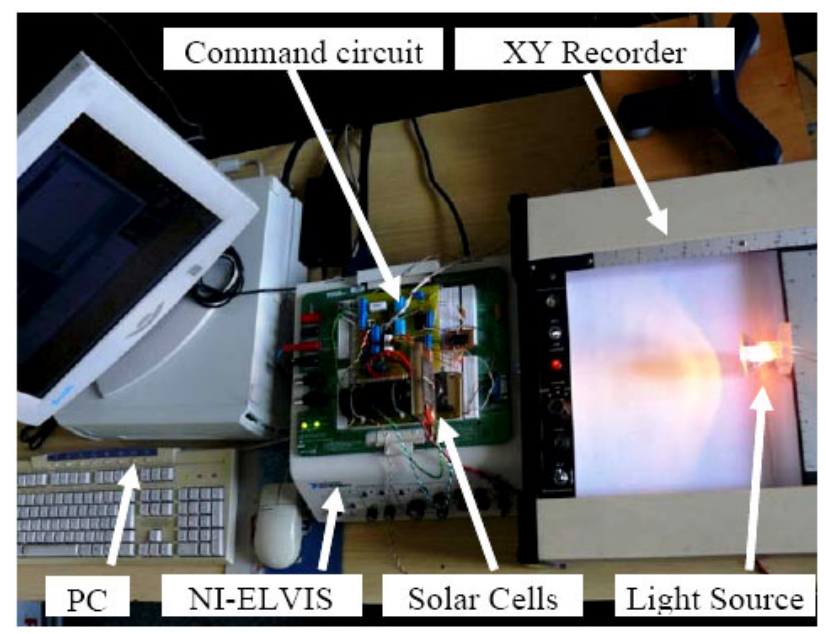

Figure 4. The solar cells automated measurement system for remote laboratories 


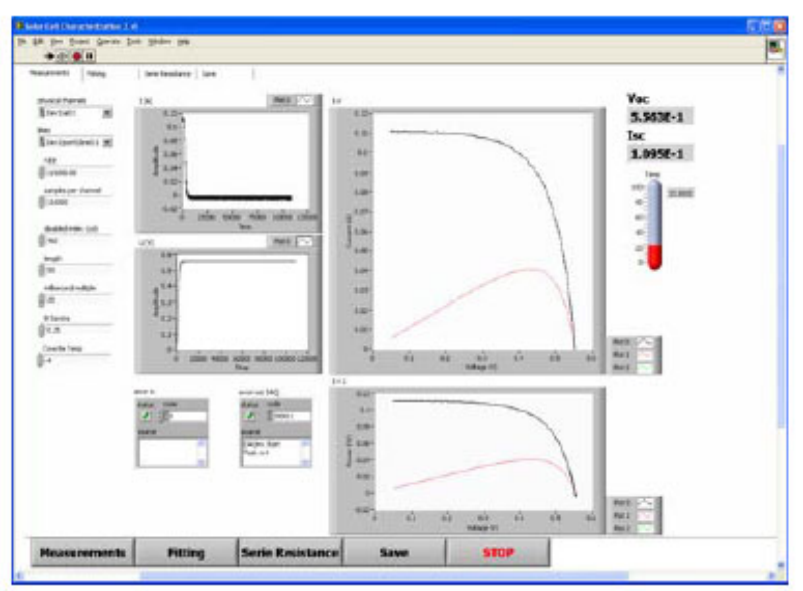

Figure 5. The interface of solar cells characterization

It is constructed on modules:

- The first module called "Measurements" - it performs the raising of the I-V and P-V characteristic;

- The second module called "Fitting" - it realizes the fitting of the I-V characteristic and determination of the solar cells parameters;

- The third module called "Series resistance" - it is complex, containing several sub modules which allow the use of various methods to determine the series resistance (the original method, the area method, the generalized area method, the simplified method of the maximum point, the method of Quanxi, the maximum power point method);

- The fourth module called "Save" - allows the saving of measured data.

The "Fig. 6" presents the user interface for "The two characteristics method" application. This application allows the series resistance determination by reading the measured data by the "Measurements" module of the general application used for raising the I-V characteristics. Taking into account the data for two characteristics, the I$\mathrm{V}$ curves are raised for two different illumination levels. The equation (2) is used to obtain the series resistance.

$$
R_{s}=\frac{\Delta V_{1}}{\Delta I_{s c}}
$$

The differences for current (the short circuit current) and voltage were realized simultaneously by the "Poz" control. This control changes the position of the slides simultaneously on the two curves chosen, to ensure the fulfillment of the condition that the difference $\mathrm{I}_{\mathrm{sc}}-\mathrm{I}_{\mathrm{ale}} \mathrm{S}$ is constant for both curves. The slides are positioned on the curves somewhere around the point $\mathrm{P}_{\max }$. The series resistance $\mathrm{R}_{\mathrm{s}}$ is listed by the indicator "Rezl Serie".

As three equations are compulsory for the three unknown terms, the use of "The generalized area method" requires three illumination levels. The method offers the determination of the shunt and series resistance and also of the ideality factor of the diode. The programme has two main components, see "Fig. 7". A component reads the measured data and raises the three characteristics. The area between the graphs and the coordinates' axis is computed in this purpose, using the integrating function of-

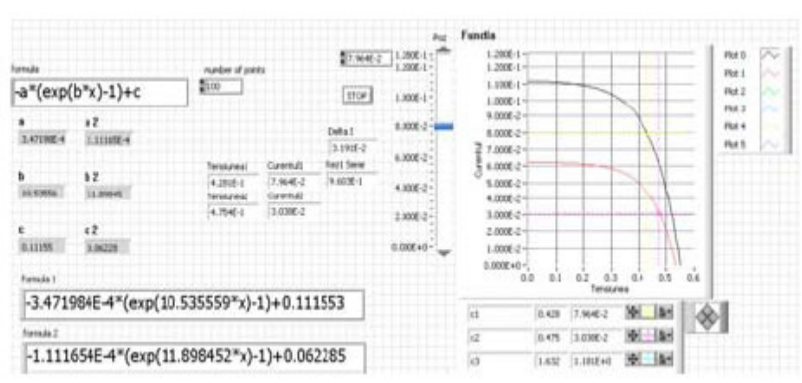

Figure 6. The interface for "The two characteristics method" application

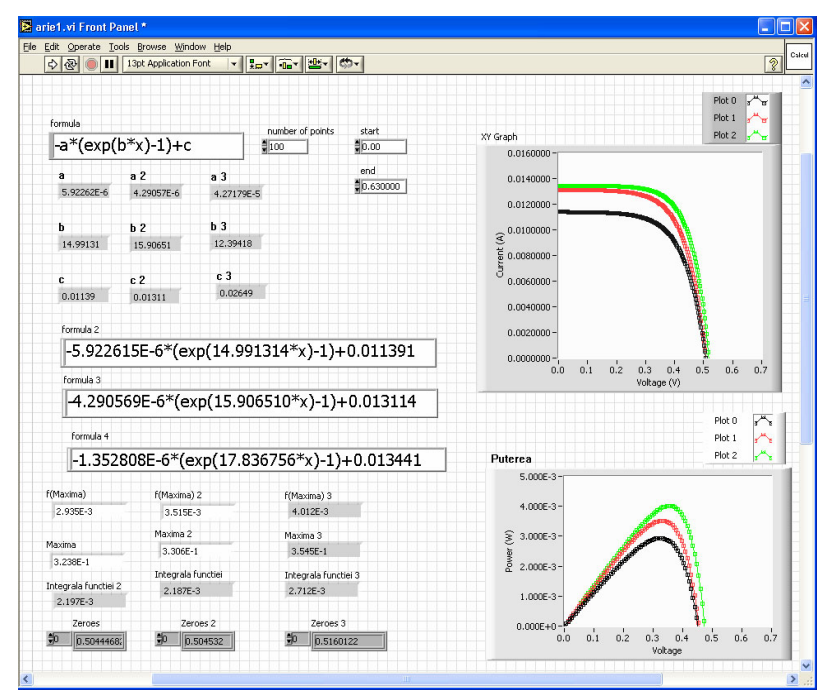

Figure 7. The interface for the application "The generalized area method"

fered by the programme. The zeros of the functions representing the open circuit voltage are calculated. All the coefficients for the system (3) are thus obtained. The second component of the programme offers the solving of the system (3), a non-linear system of three equations. The programme offers the results for the three unknown terms, having as entry parameters the data from the first part of the programme.

$\rho_{i}=\left(\frac{I_{s c}}{2 V_{o c}}\right)_{i} r+\left(\frac{1}{V_{o c}}\right)_{i} m+\left(\frac{V_{o c}}{2 I_{s c}}\right)_{i} g-\left(\frac{1}{I_{s c}}\right)_{i} \gamma g m$

where:

$$
\rho_{i}=\left(\frac{I_{s c} V_{o c}-A}{I_{s c} V_{o c}}\right)_{i} ; r=R_{s} ; \gamma=\frac{k T}{q} \text { and } g=\frac{1}{R_{s h}}
$$

\section{The Remote Applications for solar cells characterization}

This paragraph is dedicated to the presentation of web interfaces of four applications created to study the solar cells, as in [10].

The first interface is dedicated to the study of the dependence of solar cells parameters on the illumination level. The variation of the illumination level is realized by moving the light source at different distances from the cell. Adjusting this distance is done by commanding the $\mathrm{X}$ 


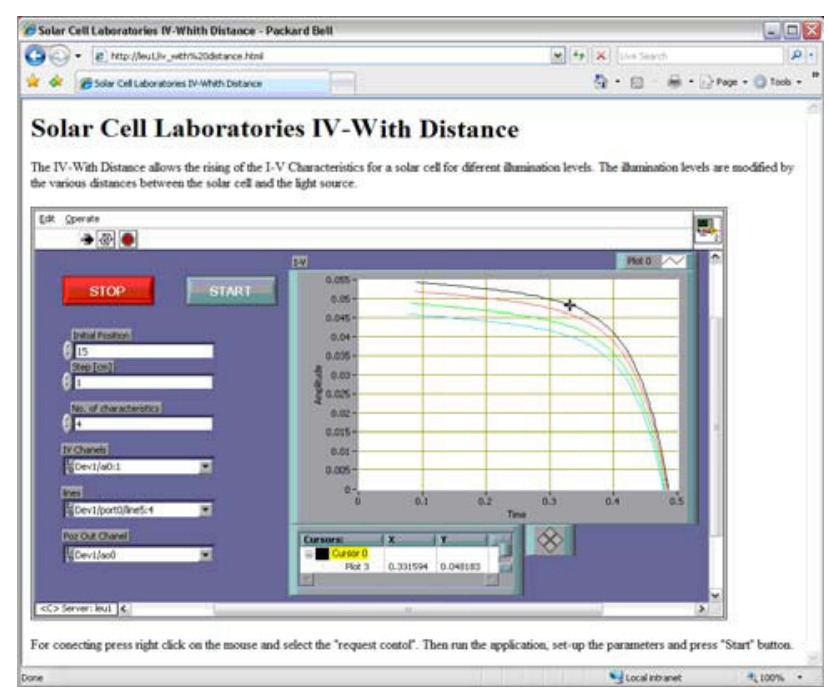

Figure 8. The web page containing the I-V with Distance remote application

input of the XY recorder. By adjusting the voltage at the $\mathrm{XY}$ command of the recorder the source can be positioned at the desired distance.

The distance on which the light source can be moved is of $20 \mathrm{~cm}$, the distance on which the illumination level varies from $1000 \mathrm{~W} / \mathrm{m}^{2}$ to $100 \mathrm{~W} / \mathrm{m}^{2}$. For the security of the system the maximum limits were fixed for the moving of the light source. In the same purpose the light source is active only during the experiment, so that the student is not allowed to surpass the limits admitted for the system.

The interface allows the student to choose the initial position (the start distance between the cell and the source), the moving step and the number of I-V characteristics to be measured. In case that by choosing these parameters, during the application execution the maximum limits fixed are surpassed, the application will stop the entire system.

By activating the cursor the students have the possibility to read the numerical data on the graph.

The second interface, "Fig. 9", allows the study of the dependence of the solar cells parameters $\left(\mathrm{V}_{\mathrm{oc}}\right.$ and $\left.\mathrm{I}_{\mathrm{sc}}\right)$ on the incidence angle of the light radiation with the cell.

The variation of the incidence angle is realized by rotating the solar cell with the help of a stepper motor.

The experiment can be performed for different illumination levels by adjusting the distance source-cell.

The study can be performed with an adjustable domain of the angle variation and with adjustable steps. The minimum step of rotating the cell is 1.80 because this is the step of the engine used. The steps can be chosen only as multiples of $1.8^{0}$. This limitation is caused by the simple command of the step by step engine that was implemented. By replacing the step by step engine with one of a lower step or by implementing a command of a half step type or multi-step, the rotation step can be lowered.

The students can visualize the evolution of the two parameters during measurements on waveform charts placed on the right of the interface (Voc and Isc). The dependence of the incidence angle is presented on the XY Graphs $\left(\mathrm{V}_{\mathrm{oc}} /\right.$ Angle and $\mathrm{I}_{\mathrm{sc}} /$ Angle) placed on the left of the interface.

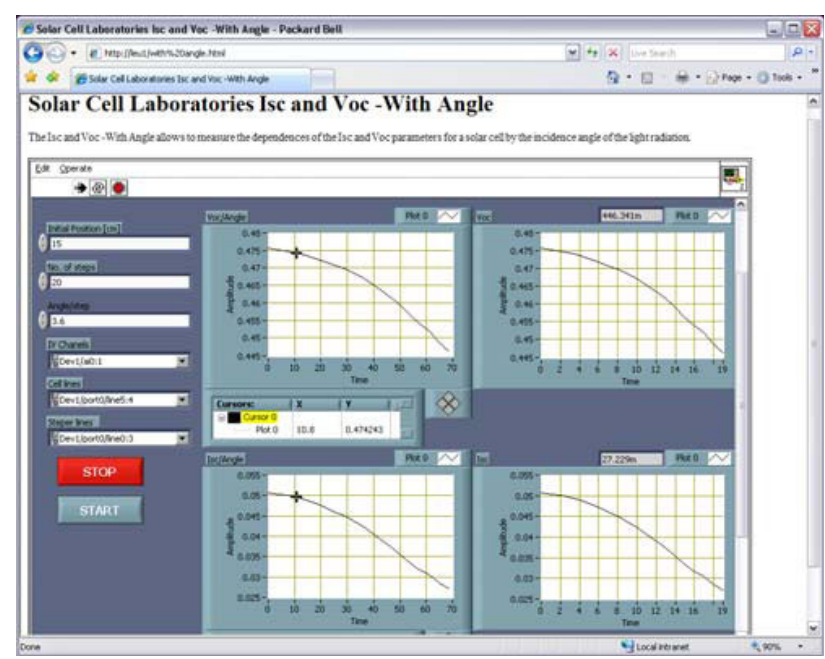

Figure 9. The web page containing the I-V with Angle remote application

As for the first application, there are implemented safety limits for the system that once surpassed lead to the stopping of the application execution and the reinitializing of the system at the start position.

The third interface allows the determination of the series resistance, Rs, using two I-V characteristics. The series resistance is determined in two steps, namely: the first is the raising of the $\mathrm{I}-\mathrm{V}$ characteristics for the cell under study (Fig.10), and the second is the mathematical processing of the data acquisitioned in the first step. The latter refers to data fitting, calculating the power characteristic and determining the maximum power and the series resistance using the data for the two I-V characteristics around the maximum power, (Fig.11).

The fourth interface shows the method to calculate the ideality factor using the dependence of Voc and Isc parameters on the light radiation levels (Fig.12).

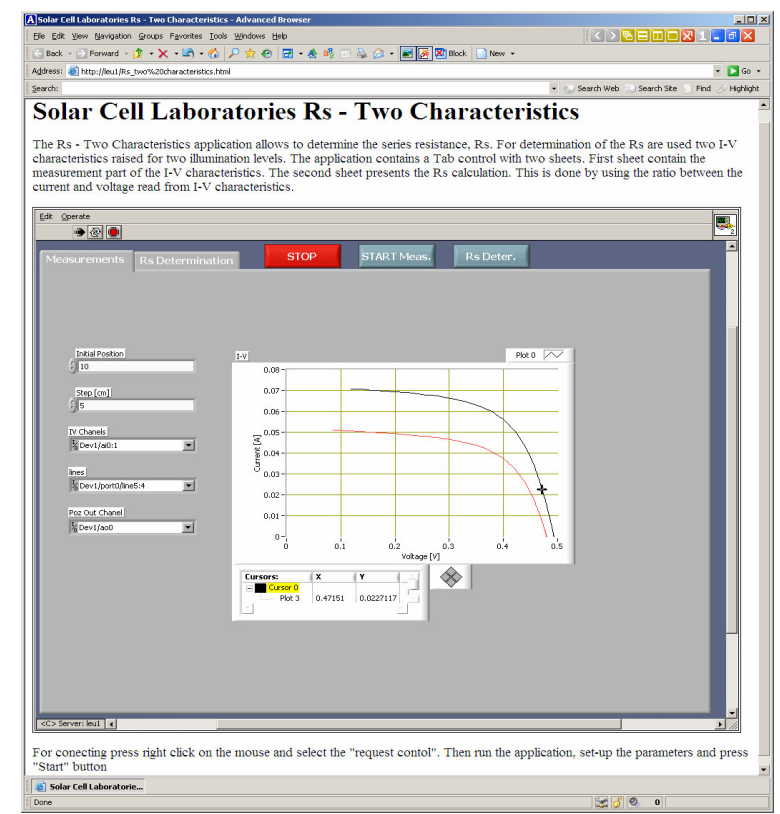

Figure 10. The web page containing the Rs - Two Characteristics remote application. The rising I-V characteristics part 


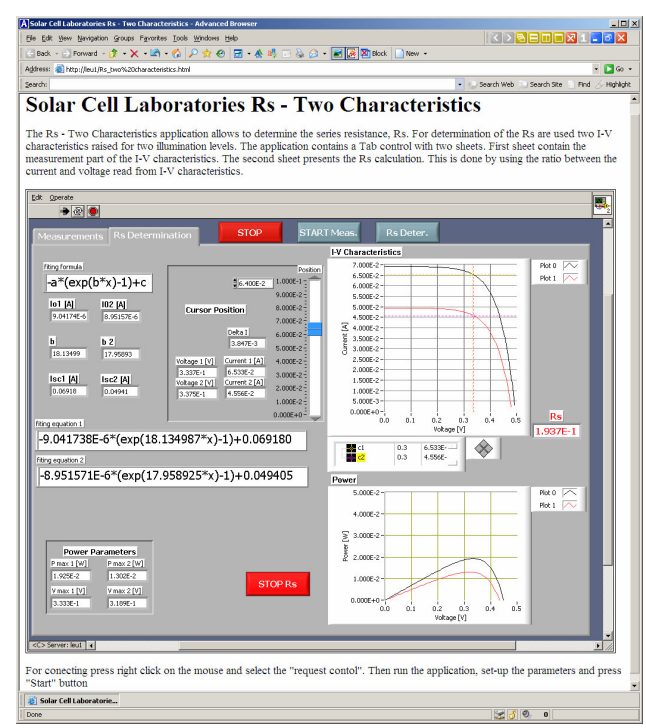

Figure 11. The web page containing the Rs - Two Characteristics remote application. The processing data part

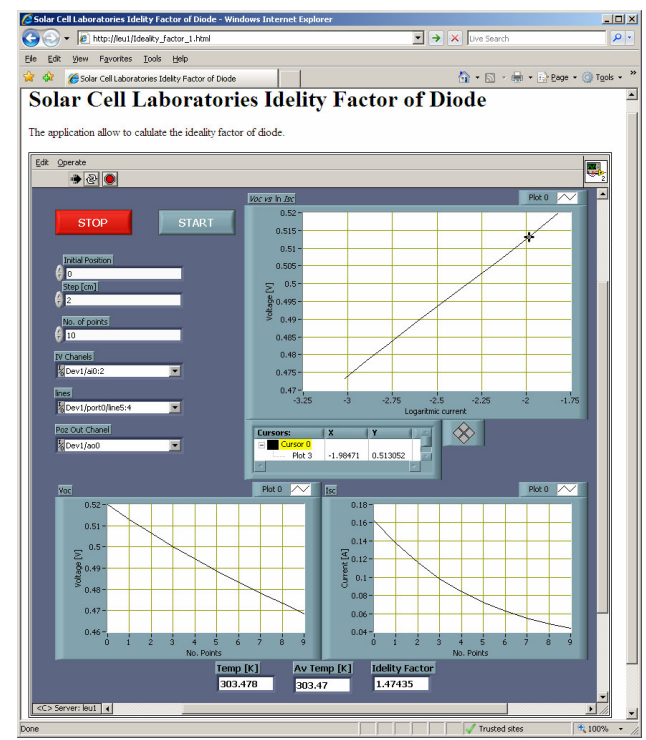

Figure 12. The web page containing the Ideality Factor remote application

\section{CONCLUSIONS}

Understanding and using the alternative energies represents a priority at European or even world level. Within this area of interests the realization of laboratories dedicated to the study of alternative energies becomes an important direction in education.

The realized applications allow the students to better understand all the aspects related to the study of the photovoltaic cells used as an alternative energy source.

The usage of LabVIEW programming language allows a quick and easy implementation of the remote control of the laboratory experiments realized.

The laboratory is realized with a minimum of equipment offering its simplicity and viability in use.

The next step in developing the remote lab will be to achieve all the elements necessary for the study of the solar cells parameters: light source, the circuit for automatically raising the $\mathrm{I}-\mathrm{V}$ characteristic of the solar cell, the thermostat, the step by step engine, and the circuit for irradiance variation, on a board which can replace the a NI ELVIS prototyping platform.

\section{ACKNOWLEDGMENT}

For the support given in the realization of the electronic part of the system developed in this paper the authors would like to thank Mr. Arama Done electronics technician at the Physics department of the "Transylvania" University of Brasov.

\section{REFERENCES}

[1] Ursuțiu D.: "Initiere in LabVIEW Programare grafica in fizica si electronica”, Editura Lux Libris, Brasov, 2001.

[2] D. T. Cotfas, P. Cotfas, S. Kaplanis and D. Ursutiu, "Results on series and shunt resistances in a c-SI PV cell. Comparison using existing methods and a new one" - 8th International Balkan workshop on Applied Physics, Constanta, Romania, 5-7 June, 2007, preluat de JOURNAL OF OPTOELECTRONICS AND ADVANCED MATERIALS, Vol. 10, No. 11, pp. 3124 - 3130 November 2008.

[3] M.Bashahu and A Habyarimana, "Review and Test of Methods for Determination of the Solar Cell Series Resistance", Renewable Energy, vol. 6, pp. 128-138, 1995. (doi:10.1016/09601481(94)E0021-V)

[4] B. Arcipiani, "Generalization of the area method for the determination of the parameters of a non-ideal solar cell", Rev. phys. Appl., vol. 20, pp. 269-272, 1985. (doi:10.1051/ rphysap:01985002005026900)

[5] Mohan Lal Priyanka and S.N. Singh "A new method of determination of series and shunt resistances of silicon solar cells", Solar Energy Materials \& Solar Cells, vol. 91, pp. 137-142, 2007. (doi:10.1016/j.solmat.2006.07.008)

[6] D. T. Cotfas: $\mathrm{PhD}$. Thesis "Investigation on parameters affecting the photoconversion efficiency in PV-cells based on $\mathrm{Si}$ and CdTe", Brasov, 2007.

[7] D.Cotfas, P.Cotfas, D.Ursutiu, S.Kaplanis, C.Samoila, "Virtual Instrumentation in the Solar Cell Characterization", REV-2007, Porto-Portugal, 24-27 of June 2007, ISBN 978-3-89958-2789, Kassel Press.

[8] Cotfas P., Ursutiu D., Samoila C., "Self Growing Remote Controlled Laboratory", International Journal of Online Engineering iJOE, Vol 2, nr 1, ISSN: 1861-2121, 2006;

[9] Luis Gomes, Javier Garcia-Zubia, "Advances on remote laboratories and e-learning experiences", University of Deustos - Spain, 310 pag, 2007, ISBN 978-84-9830-077-2;

[10] P. A. Cotfas, D. T. Cotfas, D. Ursutiu, C. Samoila: “A New Remote Laboratory for the Photovoltaic Cells Study", International Conference Remote Engineering and Virtual Instrumentation REV2008, Dusseldorf, June, 2008, Kassel Press, ISBN978-389958-352-6.

\section{AUTHORS}

P.A. Cotfas, Lecturer Dr., Transylvania University of Brasov, Department of Physics, 29 Bd-ul Eroilor Brasov, cod 500036, Romania (e-mail: pcotfas@unitbv.ro).

D.T. Cotfas, Lecturer Dr., Transylvania University of Brasov, Department of Physics, 29 Bd-ul Eroilor Brasov, cod 500036, Romania (e-mail: dtcotfas@unitbv.ro).

D. Ursutiu, Prof. Dr., Transylvania University of Brasov, Department of Physics, 29 Bd-ul Eroilor Brasov, cod 500036, Romania (e-mail: udoru@unitbv.ro).

C. Samoila, Prof. Eng. Dr., Transylvania University of Brasov, Department of Science of Materials, 29 Bd-ul Eroilor Brasov, cod 500036, Romania (csam@unitbv.ro).

Submitted, March, 30, 2009. Published as resubmitted by the authors on July, 15, 2009. 